\title{
Assessing expertise using eye tracking in a Virtual Reality flight simulation.
}

${ }^{*}$ Harris, D.J. ${ }^{1,2}$, *Arthur, T. ${ }^{1,2}$, de Burgh, T. ${ }^{1}$, Duxbury, M. ${ }^{1}$, Lockett-Kirk, R. ${ }^{1}$, McBarnett, W. ${ }^{3}$, Vine, S.J. ${ }^{1,2}$

*Joint first author

1: School of Sport and Health Sciences, University of Exeter, Exeter, UK, EX1 2LU

D.J.Harris@exeter.ac.uk, S.J.Vine@exeter.ac.uk, T.T.Arthur@exeter.ac.uk

2: Cineon Training, The Old School, Clyst Honiton, Exeter, EX5 2LZ toby@cineon.training, ross@cineon.training, mike@cineon.training

3: Aquila Jet Training, 184 Rashee Road, Ballyclare, Northern Ireland, BT39 9JB aquilajettraining@gmail.com

\section{Author note}

Correspondence concerning this article should be addressed to Dr David Harris, School of Sport and Health Sciences, University of Exeter, St Luke's Campus, Exeter, EX1 2LU. Contact:

D.J.Harris@exeter.ac.uk.

ORCiD: DH - https://orcid.org/0000-0003-3880-3856; SV - https://orcid.org/0000-0001-93291262

Conflict of interest - The authors declare no conflicts of interest.

Availability of data, material and code - All relevant data and code is available online from: https://osf.io/c2tz9/ 


\title{
Assessing expertise using eye tracking in a Virtual Reality flight simulation
}

\begin{abstract}
1 Objective: The aim of this work was to examine the fidelity and validity of an aviation 2 simulation using eye tracking. Background: Commercial head-mounted virtual 3 reality (VR) systems offer a convenient and cost-effective alternative to existing 4 aviation simulation (e.g., for refresher exercises). We performed pre-implementation 5 testing of a novel aviation simulation, designed for head-mounted VR, to determine 6 its fidelity and validity as a training device. Method: Eighteen airline pilots, with 7 varying levels of flight experience, completed a sequence of training 'flows'. Self8 reported measures of presence and workload and users' perceptions of fidelity were 9 taken. Pilots' eye movements and performance were recorded to determine whether 10 more experienced pilots showed distinct performance and eye gaze profiles in the 11 simulation, as they would in the real-world. Results: Real-world expertise correlated 12 with eye gaze patterns characterised by fewer, but longer, fixations and a scan path 13 that was more structured and less random. Multidimensional scaling analyses also 14 indicated differential clustering of strategies in more versus less experienced pilots.

15 Subjective ratings of performance, however, showed little relationship with real-world 16 expertise or eye movements. Conclusion: We adopted an evidence-based 17 approach to assessing the fidelity and validity of a VR flight training tool. Pilot reports 18 indicated the simulation was realistic and potentially useful for training, while direct 19 measurement of eye movements was useful for establishing construct validity and 20 psychological fidelity of the simulation.
\end{abstract}

Keywords: VR; simulated; flight; competency 
Alongside surgery, the aviation industry has traditionally led the way in developing high-fidelity synthetic training environments (e.g., see Caro, 1973). However, despite being highly advanced and widely accepted within the field, aircraft simulators are very expensive and often hard to access. Therefore, there is a niche for more cost-effective and portable methods of simulation to bridge the gap between classroom instruction and high-fidelity aviation simulators. Commercial standalone virtual reality (VR) headsets could address this need and provide additional flexibility for preparatory or refresher training. The value of this approach for addressing skill fade issues has been highlighted by the recent pandemic, where more than two-thirds of the world's 22,000 mainline passenger airliners were grounded at one point (Source: flightglobal.com). Consequently, new methods for refresher training need to be developed and tested.

For commercial VR technologies to be effective in aviation training, they must support sufficient transfer of learning from the VR environment to the real environment (see Barnett \& Ceci, 2002). Indeed, the ultimate test of a VR training environment is not whether it looks and feels authentic, but whether it generates improvements in realworld skilled performance. Crucially, various outcomes that predict transfer of learning can be determined before a simulation is implemented. Harris and colleagues (Harris, Bird, et al., 2020) have recently outlined a conceptual framework to help guide such evidence-based testing, through evaluating whether training is sufficiently realistic to drive 'real-world' skill improvements. The present work adopts these recommendations to examine a novel VR flight simulator, designed to (re)train flight competencies in commercial airline pilots.

Harris et al. (2020) outline fidelity and validity as key concepts for preimplementation testing of simulated environments. Fidelity refers to the realism of the simulator; in particular, the similarity of the visual elements with the real environment, but also the realism of the affective states, cognitions, or behaviours that the simulation elicits from its users (Gray, 2019; Harris, Bird, et al., 2020; Perfect et al., 2014). Hence fidelity contains many subtypes, like physical, psychological, affective, and biomechanical fidelity. The most important types of fidelity will depend on the goals of the training. In a medical context, for instance, a VR exposure therapy tool which aims to desensitise the user to an aversive stimulus (e.g., Botella et al., 2007) requires high 
affective fidelity (achieving realistic emotional responses). However, realistic movements (biomechanical fidelity) will most likely be peripheral to training success. One way of assessing the overall fidelity of an environment is to measure users' sense of presence, that is their experience of actually existing inside the virtual environment (Baños et al., 2004; Slater, 2009; Slater \& Sanchez-Vives, 2016). If the environment is not sufficiently realistic to immerse the user, then their sense of presence will be limited. This is an approach that has previously been adopted when testing sporting simulators (e.g., Harris, Buckingham, et al., 2020b; Le Noury et al., 2020).

Validity refers to whether a test, model, measurement, or simulation provides an accurate representation of its real equivalent. Two key types of validity exist in the context of VR training (see Table 1): face validity, which is a user's subjective view of how realistic a simulation is, and construct validity, which is a more objective assessment of the correspondence between the real and virtual tasks (Bright et al., 2012; Wood et al., 2020). Face validity is closely related to aspects of fidelity (particularly physical fidelity) but refers to the more subjective assessment by the user of whether the technological features of the system, which constitute its fidelity, are 'good enough' to provide a compelling experience. Assessments of face validity often depend on user feedback about the realism of a simulator, as is commonly performed for surgical (Bright et al., 2012; Sankaranarayanan et al., 2016) and flight (Perfect et al., 2014) simulators. Achieving good face validity is an initial step that is important to meet, as it may be a barrier to users engaging with the training. However, it will not ensure that training is actually effective (Dahlstrom et al., 2009). Construct validity, on the other hand, depends on some level of functional correspondence between the real and VR tasks. Consequently, a good indicator of construct validity is whether real-world expertise equates to expertise in the simulator. If so, this indicates a functional correspondence between the real and VR tasks that should support effective training (Harris, Bird, et al., 2020). Comparisons of novice versus expert performers in the simulation is, then, a good way to establish construct validity (e.g., as in Bright et al., 2012; Harris, Buckingham, et al., 2020b; Wood et al., 2020). 
Table 1 - Summary of VR terminology

\begin{tabular}{ll}
\hline Term & Definition \\
\hline Face validity & $\begin{array}{l}\text { Users' perceptions of whether the environment looks and } \\
\text { feels realistic }\end{array}$ \\
\hline Construct validity & $\begin{array}{l}\text { The extent to which the simulations provides and accurate } \\
\text { representation of the real task }\end{array}$ \\
\hline Fidelity & $\begin{array}{l}\text { The extent to which a simulation recreates the real-world } \\
\text { system }\end{array}$ \\
\hline $\begin{array}{l}\text { Psychological } \\
\text { fidelity }\end{array}$ & $\begin{array}{l}\text { The realism of the perceptual and cognitive responses } \\
\text { elicited from the user }\end{array}$ \\
\hline Presence & The feeling of actually existing in the virtual world \\
\hline
\end{tabular}

86

In the present work we tested a novel aviation training tool (see Figure 1), developed for commercial VR platforms, which simulates key scenarios used in the process of commercial Type Rating pilot certification. During the early stages of training, trainee pilots are expected to quickly become familiar with the flight deck, control location, and orientation (Adanov et al., 2020; Valenta, 2018). Traditionally, this is achieved using paper mock-up flight decks and 2D computer learning. However, this approach fails to deliver on some of the keys aspects of effective learning that support transfer of training, such as active and exploratory practice (Freeman et al., 2014; Prince, 2004). The simulation described in this work aims to provide active practice of core competency drills to allow pilots to refresh their skills in a realistic way. Pilots can familiarise themselves with the flight deck and learn the position and function of controls, as well as practicing fault responses and 'flow check' procedures.

The simulation that was developed was also embedded with eye tracking technology, which is now a common feature of many commercial VR headsets. Eye tracking has been widely used in the study of human performance, both as a way to index expertise (Brams et al., 2019; Gegenfurtner et al., 2011; Janelle \& Hatfield, 2008; Wilson et al., 2015) and as a way to accelerate learning (Causer et al., 2011; Vine \& Wilson, 2011). Although eye movements are heavily context-dependent, experts generally show highly efficient gaze control and are able to extract the most important information from the environment when performing skilled actions and decision-making operations. For instance, aeronautical studies have shown that pilots' visual scanning 
strategies develop with level of expertise (Haslbeck et al., 2012; Haslbeck \& Zhang, 2017; Yang et al., 2013; Ziv, 2016), and generally reflect a move towards shorter and more frequent fixations indicative of more rapid scanning of the instruments. Lounis et al., (2021) found shorter dwell times, and more complex transition sequences as indexed by entropy and Lempel-Ziv complexity. Consequently, as well as looking at the relationship between real-world expertise and simulator performance (i.e., construct validity), we aimed to assess whether real-world experts showed different gaze behaviours in the simulation. Eye movement differences would indicate that the simulation had good psychological fidelity in that it was sufficiently realistic to elicit different cognitions and visual behaviours between novices and experts, much as the real world would (Gray, 2019; Harris, Bird, et al., 2020).

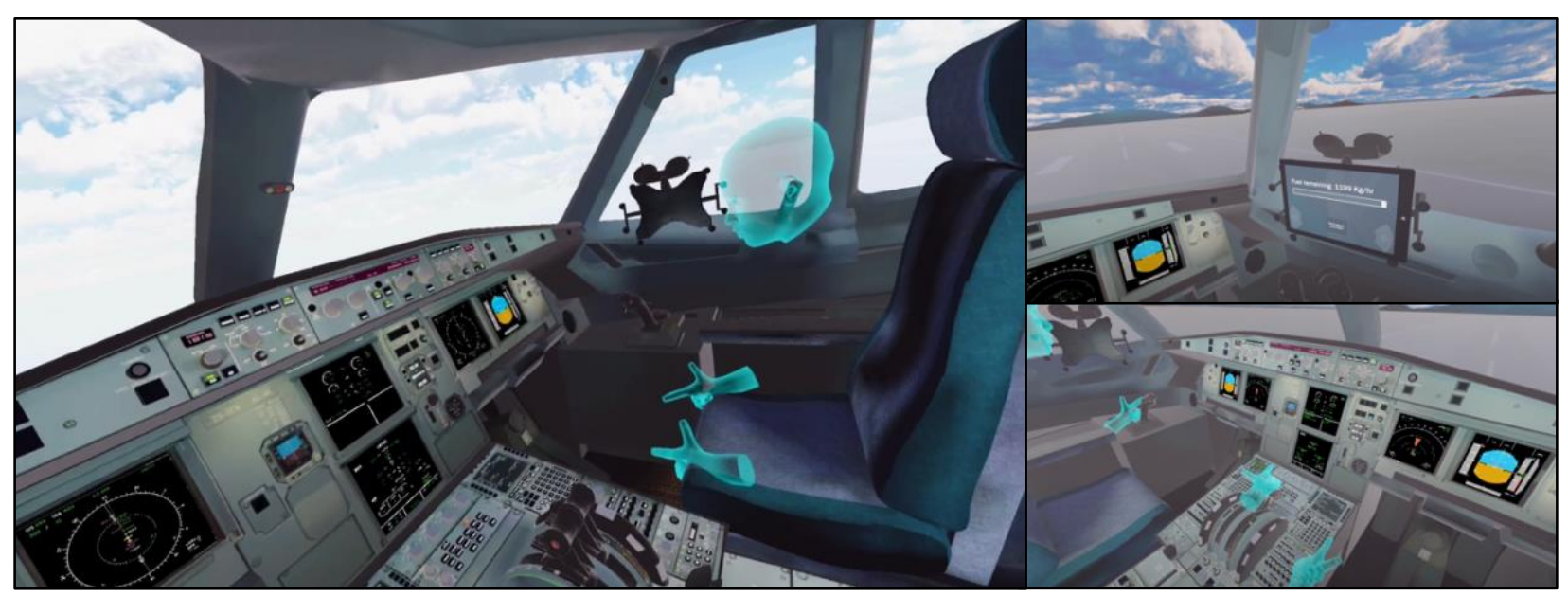

Figure 1 - View from within the simulation showing the cockpit and the pilot avatar.

In summary, the objectives of this study were to perform a number of preimplementation assessments of the aircrew competency training simulation, guided by a recent framework for testing simulated training environments (Harris, Bird, et al., 2020). Firstly, we assessed users' sense of presence in the simulation to test fidelity and collected expert reports on the face validity of the simulation as a training tool. We also aimed to assess the relationship between real-world expertise and performance (expert ratings) to establish construct validity. To further assess the construct validity and psychological fidelity of the simulation, we next examined the relationship between real-world expertise and eye movement indicators of expertise. It was predicted that if the simulation accurately recreates the demands of the real skill there should be relationships between real-world experience, performance in the simulation, and eye 
movement indicators of expertise. We implemented a dimension reduction technique,

140 known as Multidimensional Scaling, to establish whether there was a clear clustering of

141 eye gaze strategies (i.e., a signature of expertise) for more and less experienced pilots.

142 In addition, we collected descriptive measures of workload to understand the cognitive

143 and attentional demands placed on users. Together, these pre-implementation

144 assessments were designed to provide an early indicator of whether the simulation will

145 be an effective training tool.

\section{Methods}

\section{Participants}

Participants were all airline pilots, recruited through an opportunity sample of attendees at the L3 Harris Airline Academy (Crawley, Gatwick, UK). Inclusion criteria required that these individuals were familiar with $A 320$ aircraft systems, but they did not have to be type rated or have had any particular number of flight hours (real or

152 simulated). Eighteen participants (17 male, 1 female) took part in the testing.

153 Participants had a mean age of 39.2 years $(S D=14.3$, range $=22-62)$ and held a range of flight-related roles, including seven Captains, five cadets, two first officers, and two Type Rating Instructors. They had an average of 2856.2 hours flying experience on A320 series aircraft $(S D=2819.0$, range $=0-7500)$. As we used an opportunity sample to access this skilled population, no a priori power calculation was conducted, but in order to understand the type of effects we were powered to detect we ran a sensitivity analysis using $\mathrm{G}^{*}$ Power (Faul et al., 2007). For the correlational analyses, 18 participants were sufficient to detect an effect of $r=0.67$ with $90 \%$ power, $r=.6$ with $80 \%$ power, or $r=0.5$ with $60 \%$ power, given a two tailed test and $\alpha=0.05$. Prior to data collection the study procedures were reviewed by the departmental ethics review board at the University of Exeter and all participants signed an informed consent form when attending testing.

Design

We adopted an observational design with all participants completing the same

167 flight scenarios, the order of which was counterbalanced across participants to account 168 for any practice effects.

\section{Tasks and materials}


The VR environment was built using Unity (2019.4; Unity technologies, CA) and

171 C\# and displayed using the Pico Neo 2 eye headset (Pico Interactive, San Francisco,

$172 \mathrm{CA}$, US). The Pico Neo 2 headset is a 6-degrees-of-freedom standalone headset with a

$173101^{\circ}$ degree field of view and weighs 690 grams. The headset has inbuilt eye tracking

174 which records pupil position at $90 \mathrm{~Hz}$, to a spatial accuracy of $0.5^{\circ}$. The eye tracking

175 functionality was integrated into the VR environment using the Pico SDK for Unity.

176 A total of seven flight scenarios were simulated, each of which form part of the

177 Type Rating certification process that is required for flying a commercial jet. During

178 these simulations, participants interacted with a virtual flight-deck environment

179 (illustrated in Figure 1) and performed a series of tasks using the Pico hand controllers.

180 Three exercises were 'flow' scenarios, where pilots conducted a predetermined

181 sequence of actions that confirm switch positions and control settings for a given stage

182 of flight. Specifically, we simulated the After Start Flow, Taxi Flow, and After Landing

183 Flow procedures that are specified for A320 aircraft operations (see Table 2).

184 Participants undertook the role of 'Pilot Flying' for these customary safety routines and

185 were informed that they must complete each action in the correct, pre-specified order to

186 progress through the task. Furthermore, four 'fault' exercises were also simulated,

187 where pilots undertook the role of 'Pilot Monitoring' and were tasked with responding to

188 common, unanticipated flight issues through interactive electronic display checks and

189 simple procedural movements (see Table 2 for an overview). Participants were told that

190 they could take short breaks and remove the headset between scenarios, and that they

191 could take the headset off at any time if they felt uncomfortable. Some chose to take

192 breaks out of the headset between scenarios while others chose to remain in VR.

For assessment of psychological fidelity, analyses focused on gaze responses in just the Rejected Take-Off and Blue System Hydraulics faults. In the former scenario, pilots were required to perform a number of safety-critical visual checks and monitoring operations upon receiving a number of consecutive safety alerts on the runway. Such behaviours would be reflected in their dynamic gaze responses (e.g., in their fixation patterns and scanning strategies, as in Haslbeck et al., 2012; Haslbeck \& Zhang, 2017;

199 Yang et al., 2013). Conversely, the Blue System Hydraulics fault was selected because

200 it included an additional voice-over cue, where pilots were informed about an ongoing safety issue within the cabin (see Table 2). Importantly, this additional safety alert did not require a response from the pilots; it simply served to 'surprise' participants in a 
203 manner that could be potentially disruptive to their attentional control (e.g., see 204 Landman et al., 2017). Therefore, analysis focused on the efficiency of gaze control 205 during these heightened, potentially-distracting task demands. 
Table 2 - Simulated Aviation Scenarios in the Virtual-Reality Training Tool

\begin{tabular}{ll}
\hline Scenario & Overview of Simulated Procedures \\
\hline After Start Flow & $\begin{array}{l}\text { Once the engines are running, pilots are required to perform a } \\
\text { series of checks and adjustments to the ground spoilers, flap } \\
\text { levers, trim settings, and electronic display systems before the } \\
\text { parking brake can be removed. }\end{array}$ \\
\hline Taxi Flow & $\begin{array}{l}\text { After performing flight control checks, pilots are required to set } \\
\text { radars and transponder settings in preparation for take-off, in } \\
\text { addition to performing a series of prescribed brake checks and } \\
\text { electronic display configurations. }\end{array}$
\end{tabular}

\begin{tabular}{ll}
\hline After Landing & Having landed and stopped on the taxiway, pilots are required \\
Flow & to check that a number of flight deck switches are set to \\
'off/standby/normal' settings (e.g., Predictive Windshear \\
Switch, engine mode, flap levers). They can then start the \\
Auxiliary Power Unit prior to main engine shutdown.
\end{tabular}

Blue System A fault with the Blue System Hydraulics occurs when cruising Hydraulics Fault at 35,000ft. Pilots must resolve the issue through reducing system pressure, which causes a secondary failure. Both faults require adjustments to be made on the overhead panels and electronic displays. Note: while dealing with these successive tasks, pilots received an auditory alert about an Oven fire in the cabin. This separate issue was resolved without any further actions.

Rejected Take-Off Take-off procedures are initiated, however a windshear alert on Fault the runway, causes the attempt to be aborted. Pilots are required to monitor electronic display indicators and to perform various standardised safety operations until the plane has stopped and the parking brakes have been applied.

Engine 1 Control With the aircraft in cruise, indications for engine 1 are Fault unexpectedly lost. Pilots must identify and resolve the failure, through a series of actions on the electronic display systems. Changes to the engine systems must then be monitored, in accordance with standardised aircraft operating procedures.

\section{Airpack System Overheat Fault}

Pilots are alerted that the primary Airpack system has overheated. After switching to a secondary system, its temperature gradually returns to normal levels. Pilots can monitor these changes on the electronic display panels and reinstate the primary system once the issue is resolved. They must also monitor safety cues and evaluate potential emergency actions. 


\section{Expertise}

To quantify flying expertise, participants self-reported the following information:

211 total number of flying hours accumulated on A320 aircrafts; command hours on

212 Generation 3 or 4 commercial aircrafts ${ }^{1}$; and number of months since their last A320

213 flight.

\section{Self-report}

215 After undergoing all flight scenarios participants removed their headset and completed 216 the following self-report measures:

217 Presence. To understand the user experience and the fidelity of the

218 environment, participants reported their experience of presence using a validated 219 questionnaire (the Presence Questionnaire; see Slater, Usoh, \& Steed, 1995). The 220 Presence Questionnaire consists of six questions (each on a scale of 1-7) about whether users felt as though they really existed in the VR environment. Interpretation was based on the scale anchors, with scores above the mid-point indicating that users felt more like they existed in the virtual world than the real world (as in Usoh et al., 224 2000).

Workload. The Simulation Task Load Index (SIM-TLX; Harris et al., 2019) was used to assess the level of cognitive demand experienced during the simulation. The SIM-TLX is an adaptation of the NASA-TLX (Hart \& Staveland, 1988) for measuring workload in VR. A 21-point scale is used to index the following nine bipolar workload dimensions: mental demands; physical demands; temporal demands; frustration; task complexity; situational stress; distractions; perceptual strain; and task control. The participant is asked to rate the level of demand they felt during the preceding task for each of the nine aspects of workload from 'very low' to 'very high'. This allows different aspects of workload to be assessed individually. The SIM-TLX has been used

234 previously for evaluating VR training environments (Harris, Hardcastle, et al., 2021;

235 Sudiarno \& Wahyuni, 2020).

\footnotetext{
${ }^{1}$ Generation 3 commercial aircraft refers to those introduced since the early 1980s which took advantage of digital technologies to introduce glass cockpits with flight management systems and navigation displays. Generation 4 aircraft are those that entered service since 1988, such as the Airbus A320, and use fly-by-wire technology with flight envelope protection functions.
} 
Face validity. We used a bespoke questionnaire to assess the face validity of

237 the simulation. On a scale of 1-10, participants were asked to indicate whether they

238 thought the environment and the movements were convincing, whether they would be

239 motivated to use the tool again, and whether they thought it would be a useful training

240 device (full questionnaire is available here: https://osf.io/c2tz9/). Values that are above

241 the mid-point on this scale (i.e., $\geq 6$ ) indicate support for these itemised statements.

242 Performance

243 Task performance in the two fault scenarios was scored by an expert flight

244 trainer. The behaviour of all the participants was saved in a custom binary file which

245 enabled each of the scenarios to be replayed by the research team. The expert trainer

246 rated pilot's performance in relation to the following domains: knowledge; leadership

247 and teamwork; problem solving; situational awareness; workload management;

248 application of knowledge, and communication. Scores were aggregated to provide an

249 overall performance metric. When some of the performance domains could not be

250 accurately assessed (e.g., if the recording temporarily froze), the performance score

251 was aggregated over the remaining dimensions ${ }^{2}$.

\section{Eye movements}

The following metrics were used to index pilots' strategy for scanning and monitoring the displays during the fault scenarios.

Entropy. Entropy, as a concept from information theory (Shannon, 1948), describes uncertainty about outcomes. When applied to eye tracking it indexes the level of randomness or variability in eye movements and has been previously used in assessing aviation performance (Allsop \& Gray, 2014; Lounis et al., 2021; Vine et al., 2015) and can index whether a pilot is performing a structured and systematic scanning pattern, or a highly variable and inefficient one (Lounis et al., 2021). We adopted a simple measure of entropy described by Shannon and Weaver (1949), sometimes referred to as Gaze Transition Entropy (Lounis et al., 2021) which quantifies the complexity of the scan in 'bits', according to the formula:

\footnotetext{
${ }^{2}$ This occurred for five participants on either of the two fault scenarios.
} 


$$
\text { Entropy }=\sum_{i=1}^{n} p(i)\left[\sum_{j=1}^{n} p\left(\begin{array}{c}
j \\
- \\
i
\end{array}\right) \log _{2} p\left(\begin{array}{c}
j \\
- \\
i
\end{array}\right)\right], i \neq j
$$

This formula describes the sum of the probabilities of fixating each area of interest $(\mathrm{AOI})$, conditional upon the previously fixated $\mathrm{AOI}$, with $i$ representing the "from" $\mathrm{AOI}$ and $j$ representing the "to" $\mathrm{AOI}$. If gaze location was strategic and directed at only important sequences of locations, entropy would likely be low.

Inter-saccadic angles (spatial anisotropy). The size of inter-saccadic angles can be used to describe the pathway of successive saccades. Persistent saccades continue moving in a similar direction while anti-persistent saccades return in the (approximately) opposite direction. A higher proportion of antipersistent saccades may indicate that a search has been terminated quickly, or that eye movements are moving back and forth across the cockpit a lot. Following Amor et al., (2016), we first calculated the intersaccadic angle, that is the change in angle between successive saccades and could then identify persistent and antipersistent saccades. Intersaccadic angle $\left(\theta_{d}\right)$ was defined as

$$
\theta_{d}^{i}=\arctan \left(\frac{r_{(i+1), y}}{r_{(i+1), x}}\right)-\arctan \left(\frac{r_{(i), y}}{r_{(i), x}}\right)
$$

where $r_{i, y}$ and $r_{i, x}$ are the change in the $\mathrm{x}$ and $\mathrm{y}$ components of the $i$-th saccade such that $\theta_{d}^{i}$ equates to the difference in angle between successive saccades.

\section{Persistent saccades were operationalised as those continuing in the same direction} (within $90^{\circ}$ in either direction) and antipersistent as those that changed direction (more than $90^{\circ}$ change).

Fixation rate and search rate. Fixation rate refers to the number of visual fixations made per second. Search rate is a development of fixation rate and is calculated from the number of fixations divided by duration, and indexes whether pilots are using a visual strategy of a few long fixations or dwells (low search rate) or more frequent and shorter fixations (high search rate) to attend to more locations more quickly. Search rate has previously been used as a metric to characterise visual search behaviour (Harris et al., 2021; Janelle, 2002; Williams et al., 1994) and index expertise (Janelle \& Hatfield, 2008; Mann et al., 2007). 
Saccade amplitude. The distance between the initiation location and the termination of each saccade (in degrees of visual angle) was calculated to capture whether pilots were making large shifts in their gaze location, or smaller movements to nearby areas.

296

297

298

299

300

301

302

303

304

305

306

307

308

309

310

311

312

313

314

315

316

\section{Data analysis}

Participants' combined binocular gaze vector, head position and rotation (x,y,z; pitch, yaw, roll), and gaze intersection points (i.e., where the gaze vector collided with the virtual world) were recorded from the virtual environment and analysed using an automated approach in MATLAB (Mathworks, MA, US). Eye-tracking data were first resampled to a consistent $60 \mathrm{~Hz}$ and then denoised using a dual-pass, zero-phase Butterworth filter at 30-Hz (Fooken \& Spering, 2019). Gaze fixations - periods in which the eye was stable on a location - were detected using a spatial dispersion algorithm (Krassanakis et al., 2014). Fixation events were operationally defined as clusters of successive gaze point records that fell within $1^{\circ}$ of visual angle for $>100 \mathrm{~ms}$ (Salvucci \& Goldberg, 2000). Saccades were operationalised as portions of data where gaze acceleration $\left({ }^{\circ} / \mathrm{s}^{2}\right)$ exceeded five times the median acceleration (as in Mann et al., 2019). Saccade onset and offset times were identified from acceleration minima and maxima (Fooken \& Spering, 2020). Gaze analysis code is available online:

\section{https://osf.io/c2tz9/.}

Statistical analysis was conducted using JASP v0.15 (JASP Team, 2021). Univariate outliers $(p<.001)$ for gaze and kinematic variables were identified and Windsorised by changing the outlying values to $1 \%$ larger (or smaller) than the next most extreme score (Tabachnick \& Fidell, 1996). This was only required for one fixation duration value. The demographic data for one participant was missing, so they were excluded from all analyses that required demographic data (i.e., correlations with expertise). A series of Pearson's correlations (or Spearman's where data deviated substantially from normality) were used to examine relationships between eye movement and expertise related variables. Bayes factors $\left(\mathrm{BF}_{10}\right)$, using a default Cauchy prior, were also calculated to further provide further evidence for the alternative over the null. We adopt the convention that $\mathrm{BF}_{10}>3$ indicates moderate support for the alternative model and $\mathrm{BF}_{10}>10$ indicates strong support (van Doorn et al., 2019). All anonymised data is freely available and can be accessed from the Open Science Framework (https://osf.io/c2tz9/.). 


\section{Self-report}

Face validity

The results of the face validity questions indicated that users felt as though both the environment (mean $=6.4, \mathrm{SD}=1.7$, on a $1-10$ scale) and the movements (mean $=$

$3305.9, \mathrm{SD}=1.7$ ) were convincing. There were a broader range of responses to the question 'how eager are you to have another go?' (see figure 2A), but again the mean value was above the mid-point of the scale (mean $=5.6, S D=2.9$ ). The responses to the question 'how useful do you think this is as a training device?' were also clustered in the high range (mean $=7.0, S D=1.9$ ). Overall, these results suggested a largely positive response from the pilots, that supported the fidelity of the environment and its potential utility for training.

\section{Presence}

Results in figure 2B show that presence scores clustered around and just above the mid-point of the scale (with a mean of 25.4, SD =4.2), which ranged from 6 to 42 . Users generally thought that the training tasks were believable and felt as though they really existed in the virtual environment, although four individuals did report lower scores. These scores suggest that most participants were immersed in the simulation.

\section{Workload}

The results of the workload measures (see figure $2 \mathrm{C}$ ) shows that physical demands and stress were low in the simulation, and that users did not find the task overly complex, which was as expected given the expertise of the participant group. The largest sources of workload were the perceptual strain felt by the users and some reported difficulty in controlling the simulation. However, in the context of the overall scale these scores were still low, suggesting that these factors would not have added too much extraneous load which could disrupt learning (Sweller, 1988). 
A Face validity questions

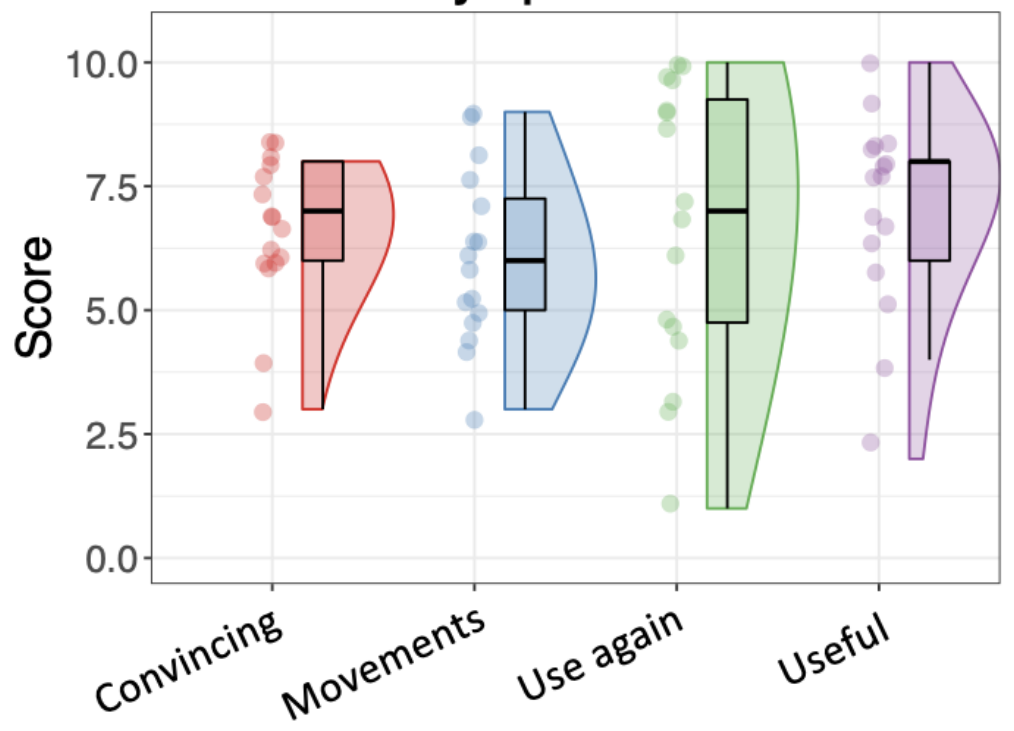

B Presence

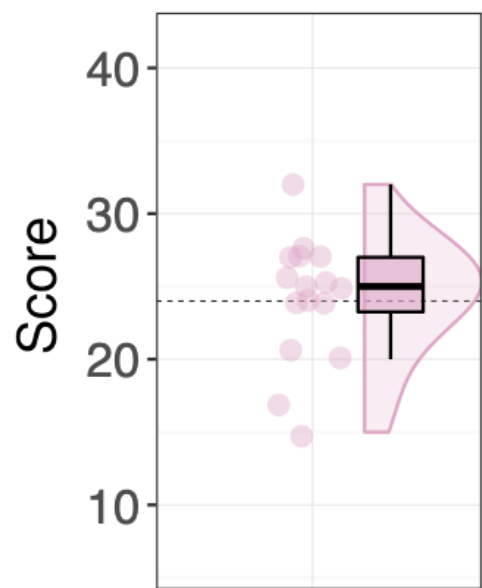

C SIM-TLX scales

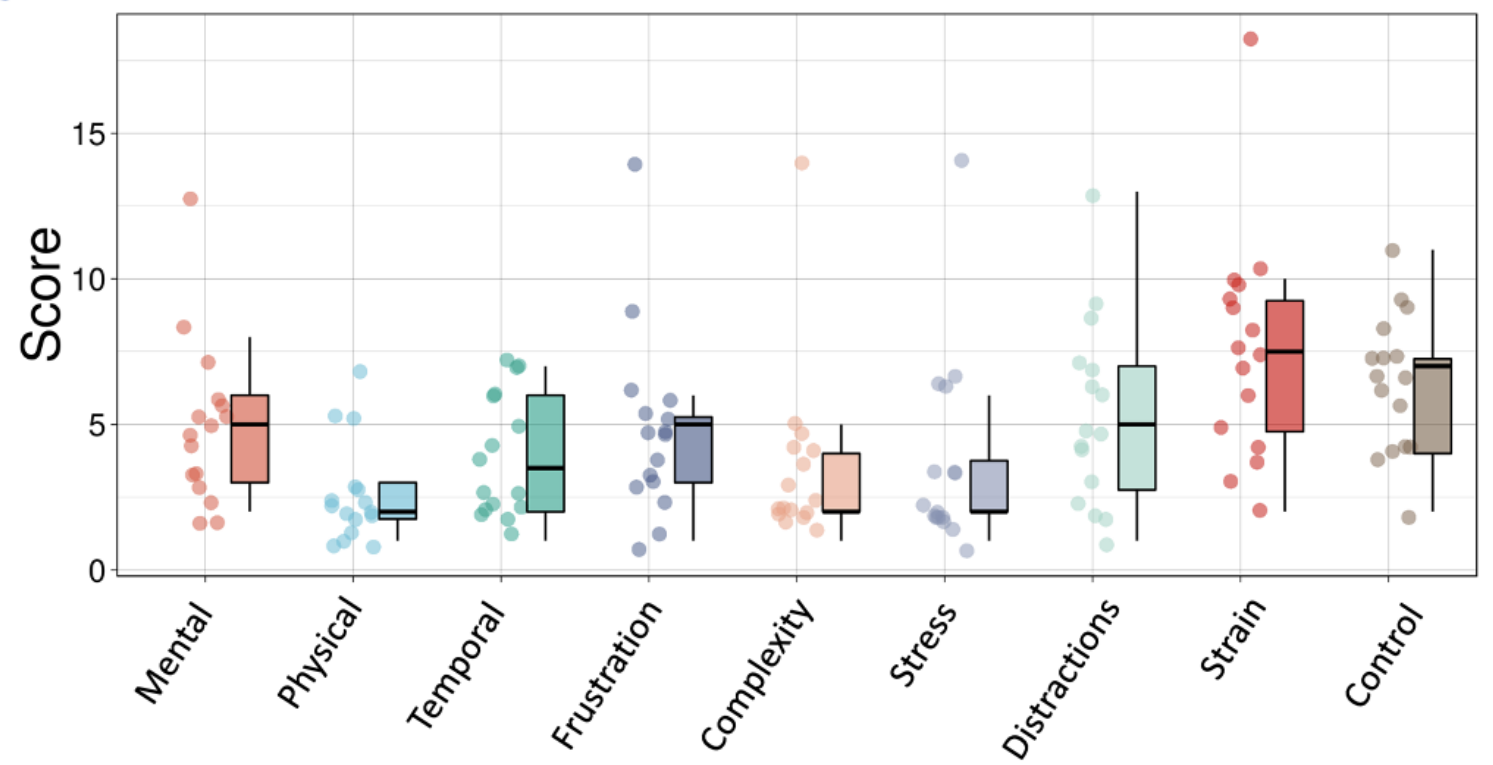

Figure 2 - A: Box and violin plot and raw data points of face validity questionnaire.

Questions were: How convincing was the virtual environment? (Convincing); How convincing were the movements? (Movements); How eager are you to have another go? (Use again); How useful do you think this is as a training device? (Useful). B: Box and violin plot of self-reported presence in the simulation. Graph axes extend to show the extremes of the scales and the dotted line shows the mid-point of the scale. C: Box plot of workload dimensions scores on the SIM-TLX. 
To understand whether performance was related to pilot experience (i.e., construct validity) we examined correlations between performance scores (trainer ratings) and $A 320$ flight hours, command hours, and time since last $A 320$ flight using Spearman's correlations, but no significant relationships were present (see Table 3).

Table 3 - results of correlations between performance scores and experience

$$
\text { A320 hours Command hours Last A320 flight }
$$

$$
\text { Performance } \quad r=.33, p=.20 \quad r=-.37, p=.21 \quad r=.04, p=.89
$$

359

\section{Relationship with eye movement metrics}

Next, we explored relationships between performance and eye movement metrics using Spearman's correlations, but only entropy approached significance ( $p=$ .053) in the blue reservoir fault. There were no other significant relationships (see Table 4).

Table 4 - results of correlations between performance scores and eye movement metrics

\begin{tabular}{llllll}
\hline & $\begin{array}{l}\text { Saccade } \\
\text { amplitude }\end{array}$ & $\begin{array}{l}\text { Antipersistent } \\
\text { saccades (\%) }\end{array}$ & $\begin{array}{l}\text { Fixation rate } \\
\text { (per second) }\end{array}$ & Search rate & $\begin{array}{l}\text { Entropy } \\
\text { (bits) }\end{array}$ \\
\hline $\begin{array}{l}\text { Rejected } \\
\text { take off }\end{array}$ & $\begin{array}{l}r=.16, p \\
=.53\end{array}$ & $r=-.11, p=.67$ & $r=.20, p=.43$ & $\begin{array}{l}r=-.03, p= \\
.92\end{array}$ & $\begin{array}{l}r=.24, p= \\
.33\end{array}$ \\
\hline $\begin{array}{l}\text { Blue } \\
\text { reservoir }\end{array}$ & $r=-.40, p$ & $r=-.24, p=.35$ & $r=.16, p=.54$ & $r=.04, p=.87$ & $r=.48, p=$ \\
.05
\end{tabular}

Relationships between eye movement metrics and expertise

To assess the construct validity of the simulations we assessed the relationship between flying experience and eye movement indices of expertise. If the simulation is a sufficiently accurate representation of the real skill then some differences between more and less skilled pilots should be detectable in the simulation. All expertise metrics were skewed so Spearman's correlations were used. 
373

374

375

376

377

378

379

380

381

382

383

384

385

386

387

388

389

390

391

\section{Rejected take-off fault}

A320 hours were weakly correlated with antipersistent saccades $[r=-0.22, p=$ .39, $\left.\mathrm{BF}_{10}=0.49\right]$, saccade amplitude $\left[r=-0.23, p=.38, \mathrm{BF}_{10}=0.46\right]$ and fixation rate $[r$ $\left.=-0.22, p=.39, \mathrm{BF}_{10}=0.46\right]$. But there was a moderate correlation with search rate $[r$ $\left.=-0.32, p=.10, \mathrm{BF}_{10}=1.30\right]$, and a strong and significant correlation with entropy $[r=-$ $\left.0.53, p=.03, \mathrm{BF}_{10}=2.79\right]$, indicating that more flight hours were related to more structured search behaviours (see Figure 3A).

Command time showed a weak correlation with antipersistent saccades $[r=-$ $\left.0.19, p=.48, \mathrm{BF}_{10}=0.50\right]$. However there were strong and significant correlations with fixation rate $\left[r=-0.55, p=.03, \mathrm{BF}_{10}=2.94\right]$, saccade amplitude $\left[r=-0.52, p=.04, \mathrm{BF}_{10}\right.$ $=2.42]$, search rate $\left[r=-0.67, p=.004, \mathrm{BF}_{10}=9.01\right]$, and entropy $[r=-0.52, p=.04$, $\left.\mathrm{BF}_{10}=1.67\right]$, which indicated that more command time corresponded to a slower (i.e., more efficient) visual search with smaller saccades, and less sporadic scan paths.

Greater time (months) since last A320 flight showed weak relationships with fixation rate $\left[r=-0.10, p=.75, \mathrm{BF}_{10}=0.39\right]$, search rate $\left[r=-0.30, p=.30, \mathrm{BF}_{10}=0.61\right]$, and entropy $\left[r=-0.29, p=.31, \mathrm{BF}_{10}=0.72\right]$, but was strongly correlated with reduced saccade amplitude $\left[r=-0.58, p=.03, \mathrm{BF}_{10}=3.60\right]$ and fewer antipersistent saccades $[r$ $\left.=-0.61, p=.02, \mathrm{BF}_{10}=4.87\right]$. These results suggest that pilots with less recent flight experience required prolonged visual searches to find specified target cues. 

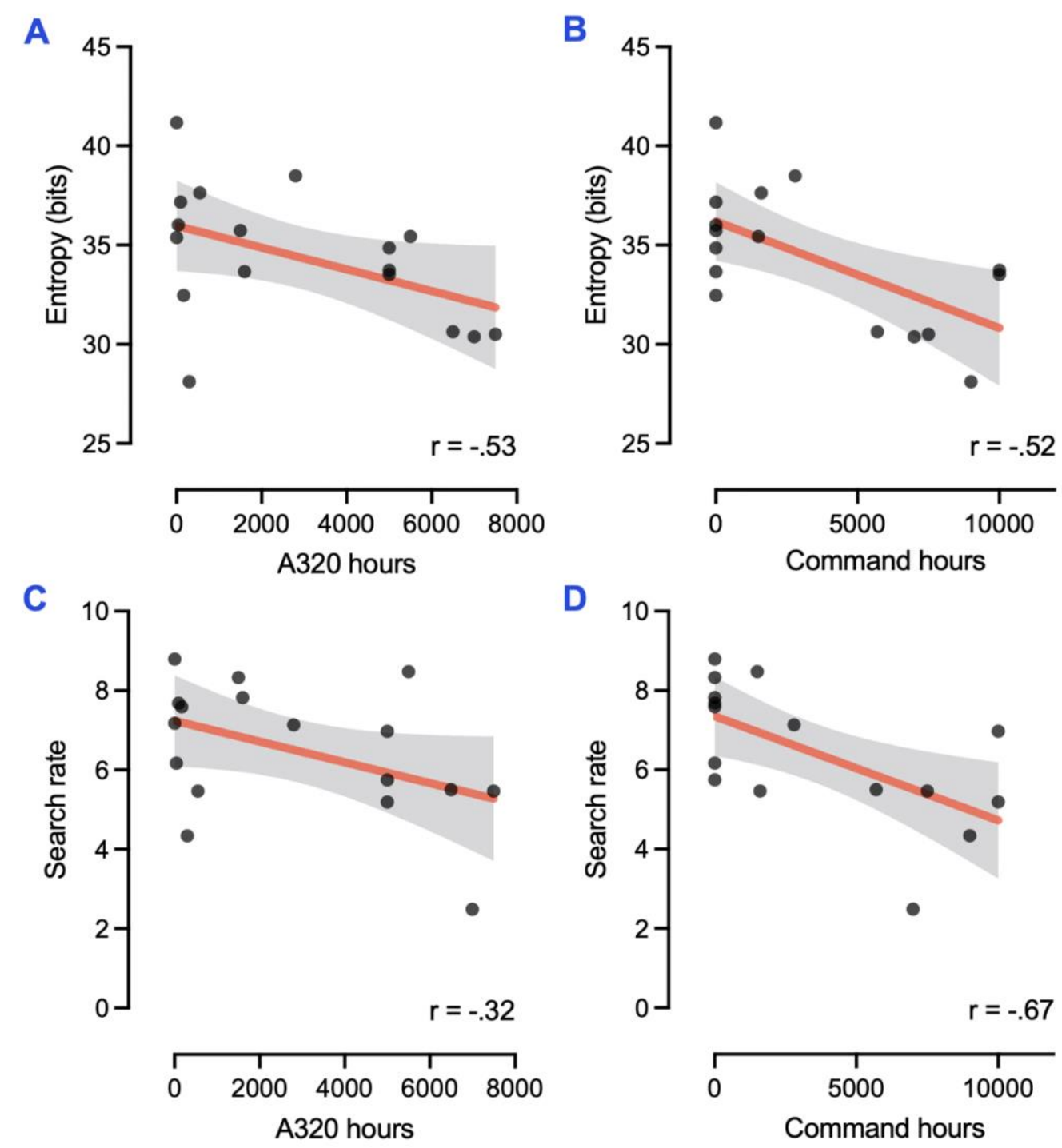

Figure 3 - Scatterplots with regression line and $95 \% \mathrm{Cls}$ for relationships between expertise and entropy ( $\mathbf{A}$ and $\mathbf{B}$ ) and search rate ( $\mathbf{C}$ and $\mathbf{D})$ for the rejected take off fault, all showing significant relationships that suggest more experienced pilots exhibited more efficient search patterns in the simulation.

\section{Blue reservoir fault}

A320 hours showed moderate but non-significant correlations with saccade amplitude $\left[r=-0.41, p=.10, \mathrm{BF}_{10}=1.00\right]$, and antipersistent saccades $[r=-0.46, p=$

$\left.396.06, \mathrm{BF}_{10}=0.89\right]$, but significant correlations with fixation rate $\left[r=-0.52, p=.03, \mathrm{BF}_{10}=\right.$ $3974.00]$, search rate $\left[r=-0.49, p=.046, \mathrm{BF}_{10}=2.79\right]$, and entropy $[r=-0.62, p=.008$,

$\left.398 \mathrm{BF}_{10}=5.76\right]$ (see Figure 4A-C). More time on A320 planes was related to slower, more 399 efficient, and less random search patterns. 
$\left.4010.33, p=.21, \mathrm{BF}_{10}=0.55\right]$, and search rate $\left[r=-0.38, p=.15, \mathrm{BF}_{10}=0.90\right]$, moderate 402 and marginally significant relationships with antipersistent saccades $[r=-0.48, p=.06$, $\left.403 \mathrm{BF}_{10}=1.41\right]$, and fixation rate $[r=-0.48, p=.06, \mathrm{BF}=1.41]$, and a strong relationship 404 with entropy $\left[r=-0.77, p<.001, \mathrm{BF}_{10}=34.35\right]$ (see Figure 4D-F).

405 Time since last A320 flight was not significantly related to saccade amplitude $[r=$ $\left.406-0.11, p=.71, \mathrm{BF}_{10}=0.37\right]$, antipersistent saccades $\left[r=-0.44, p=.12, \mathrm{BF}_{10}=1.04\right]$, 407 fixation rate $\left[r=-0.49, p=.08, \mathrm{BF}_{10}=1.28\right]$, or search rate $\left[r=-0.25, p=.39, \mathrm{BF}_{10}=\right.$ 408 0.53], but was significantly related to entropy $\left[r=-0.58, p=.03, \mathrm{BF}_{10}=3.60\right]$.

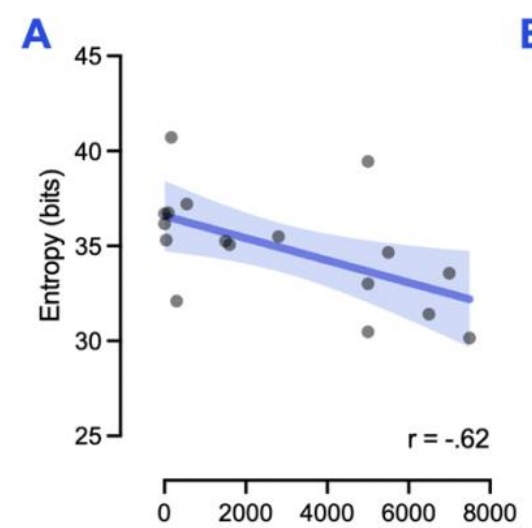

A320 hours

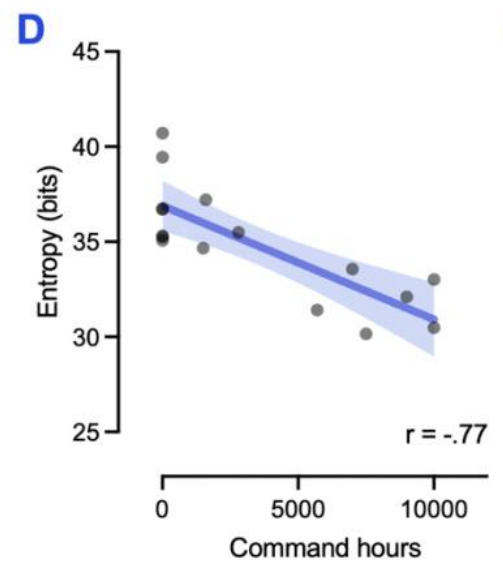

B

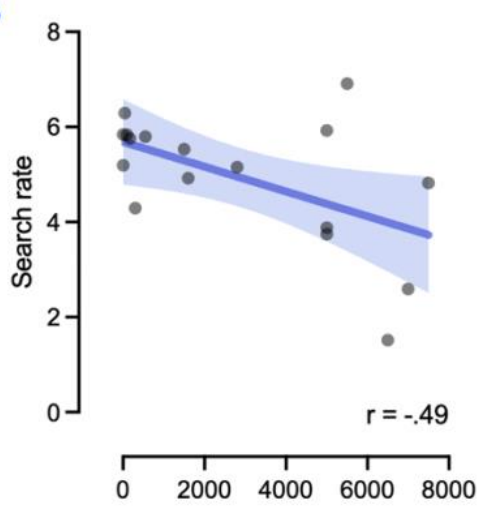

A320 hours

E

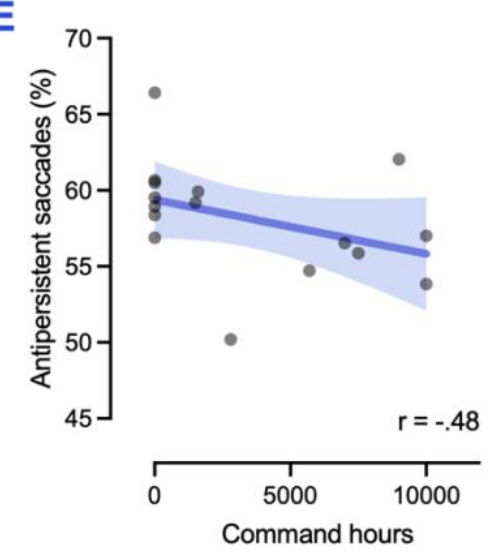

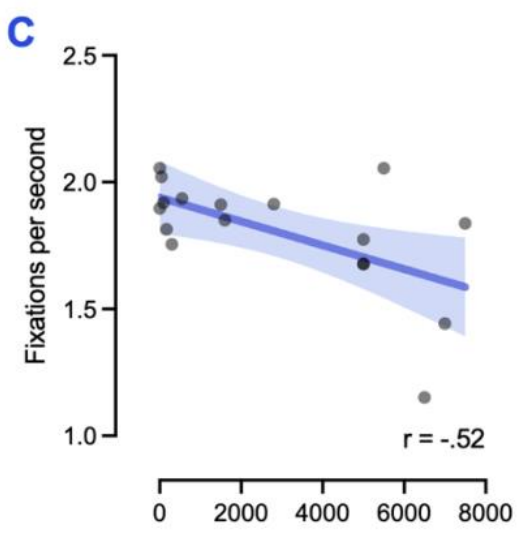

A320 hours

F

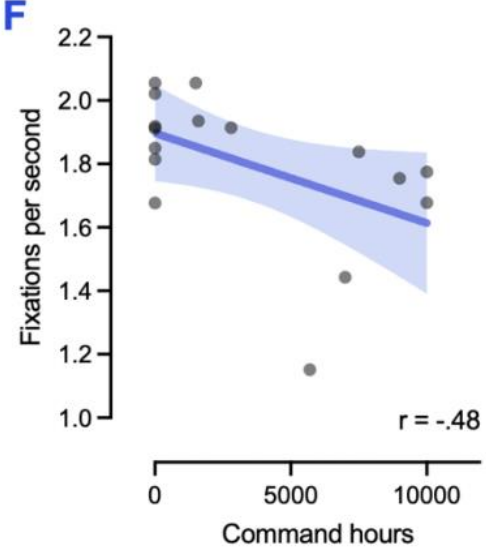

Figure 4 - Scatterplots with regression line and $95 \%$ Cls for relationships between A320 flying hours and entropy (A), search rate (B), and fixation rate (C), and between command hours and entropy (D), percentage of antipersistent saccades $(\mathbf{E})$, and fixation rate $(\mathbf{F})$. 


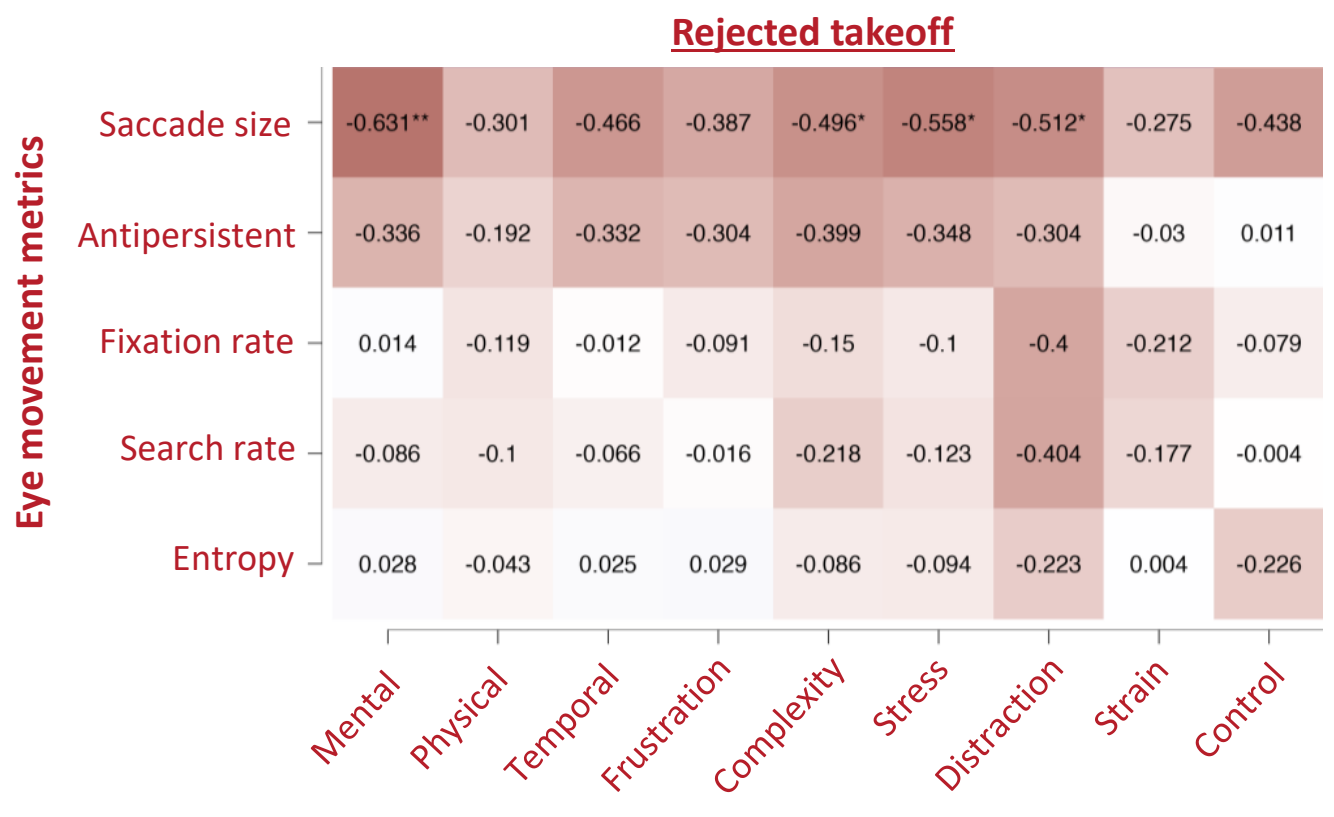

Workload dimensions

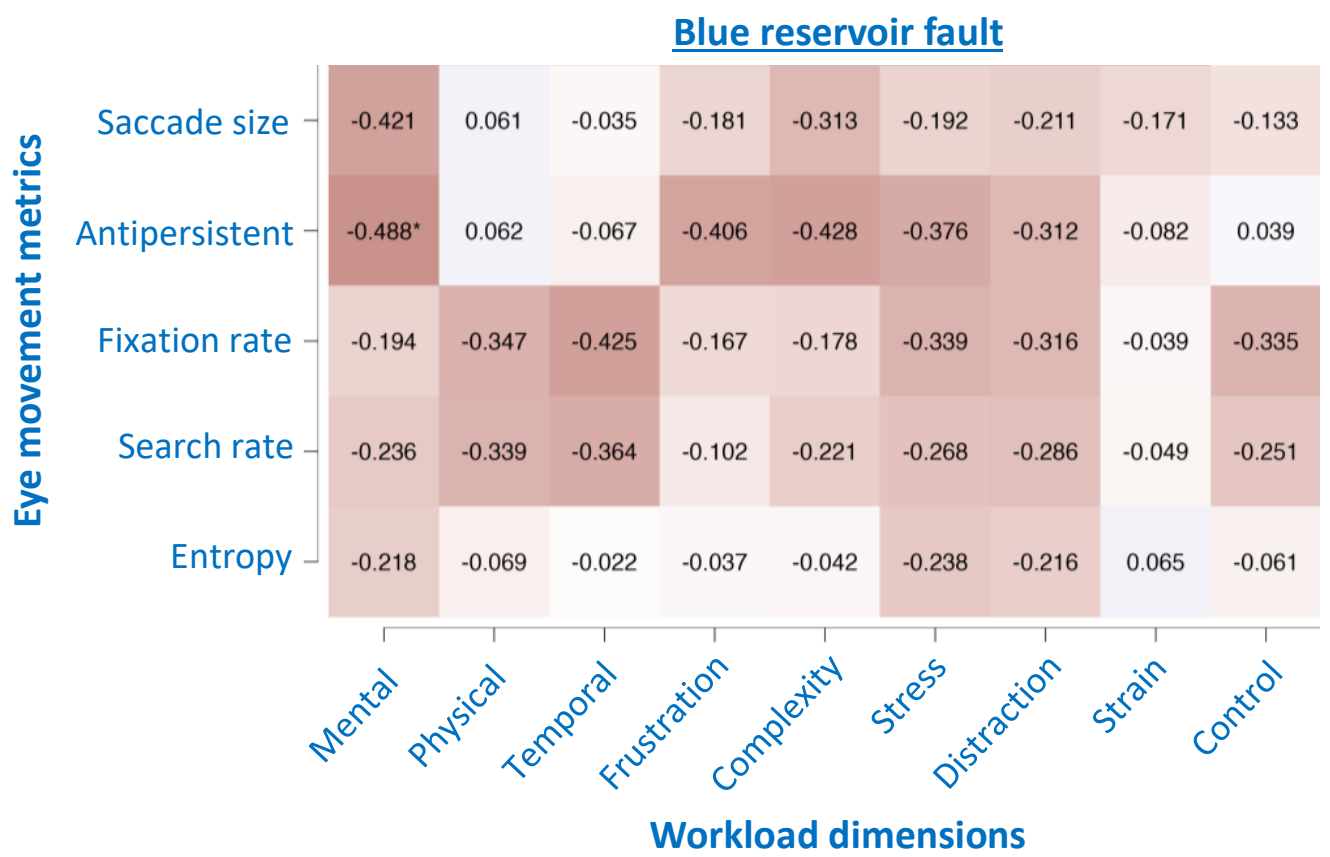

Figure 5 - Correlation heat plots between workload dimensions and eye movement metrics. Darker colours represent stronger correlations and asterisks denote significant relationships. The plots suggest that saccade amplitude appeared to be related to several workload dimensions in the rejected take-off scenario, such as mental demands, task complexity, stress, and distraction. Antipersistent saccades also showed some moderate relationships with workload dimensions across both scenarios. 
Visual search expertise may not just be indexed by singular metrics, like entropy

411 or search rate, but rather how they cluster together to form strategies. To further

412 understand the scanning strategies of the pilots, we used Multidimensional Scaling

413 (MDS) to analyse and visualise the differences and similarities between overall visual

414 scanning strategies. MDS is a dimension reduction analysis technique, similar to

415 Principal Components analysis ${ }^{3}$, that has been widely applied for visualising the 416 similarities/ differences between data sets (Borg \& Groenen, 2005). See Słowiński et 417 al., $(2016,2019)$ for applications to human movement analysis. By using MDS we can 418 represent the visual strategy of each participant as a point in an abstract geometric 419 space (where individuals who employ similar search rates, saccade amplitudes, etc, will 420 cluster) and identify principal dimensions that best explain the relationships between 421 these strategies. As is common when using MDS, we present the first two (i.e., most 422 significant) dimensions of this abstract space for visualization purposes.

The results of the MDS analysis are presented in Figure 6. The identification of the principal dimensions that explain variance in visual search strategy means that pilots with similar search rates, entropy, saccade sizes, etc, will cluster together in geometric space, allowing us to observe which individuals had similar overall strategies. This is visualized in Figure 6 Panel C, where participants were colour coded based on splitting them into 'more' and 'less' experienced, based on A320 flight hours. Visual inspection of the flight hours distribution (see Figure 6 Panel A) indicated a 430 distinct grouping of those above and below 4000hours, so this cut-off was used to 431 dichotomise the experience data for the plot. The ellipses show 95\% of the bivariate 432 normal distribution of the more and less experienced pilots. There is a clear grouping of 433 the more experienced pilots, showing that they used similar strategies. Meanwhile the 434 less experienced pilots used, for the most part, alternative strategies. a strong negative relationship with experience (both flight and command hours), and small to moderate negative relationship with trainer rated performance (Figure 6 Panel

438 D). Conversely, MDS2 had a moderate but positive relationship with experience, and 439 negative relationship with performance. These correlations further illustrate that the

\footnotetext{
${ }^{3}$ Indeed, for the current case which used Euclidean distances between individuals, MDS is equivalent to Principal Components Analysis.
} 
440 overall strategies identified by MDS captured important dimensions indicative of 441 experience and performance. 
A

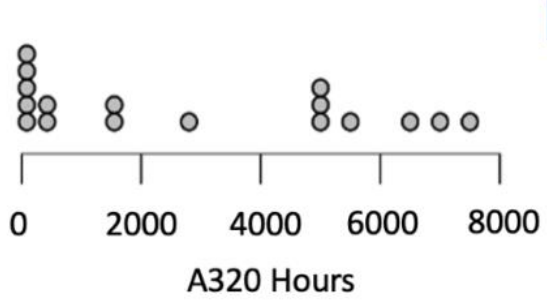

B

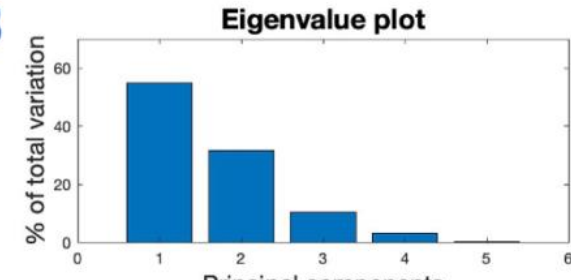

C

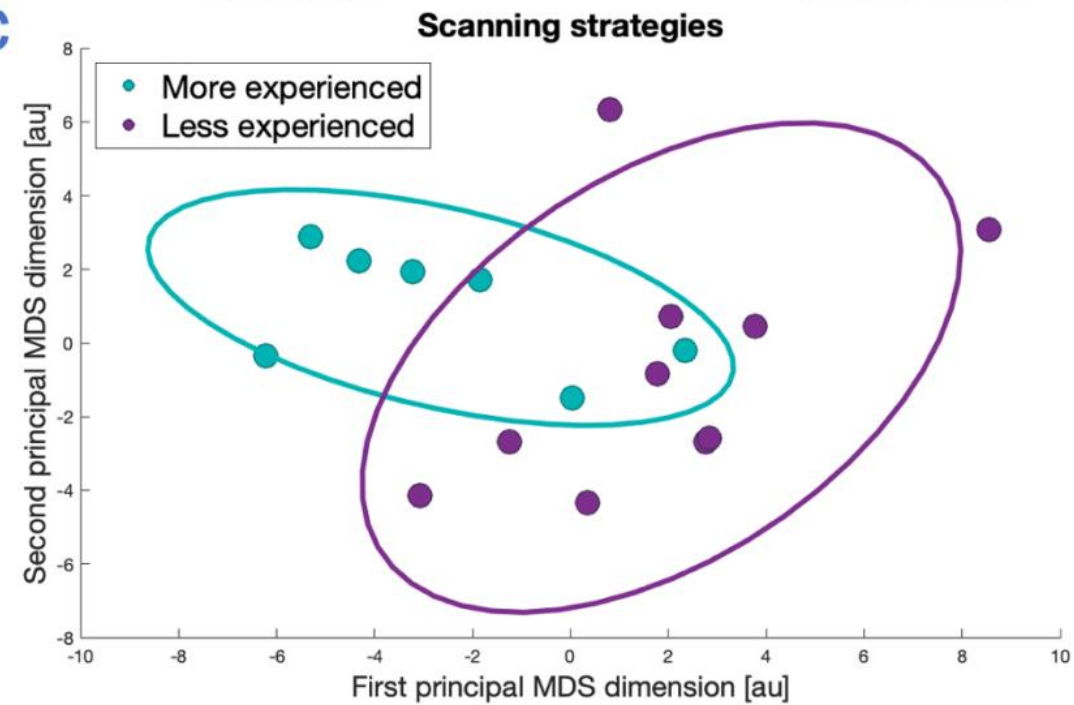

D Correlation Matrix

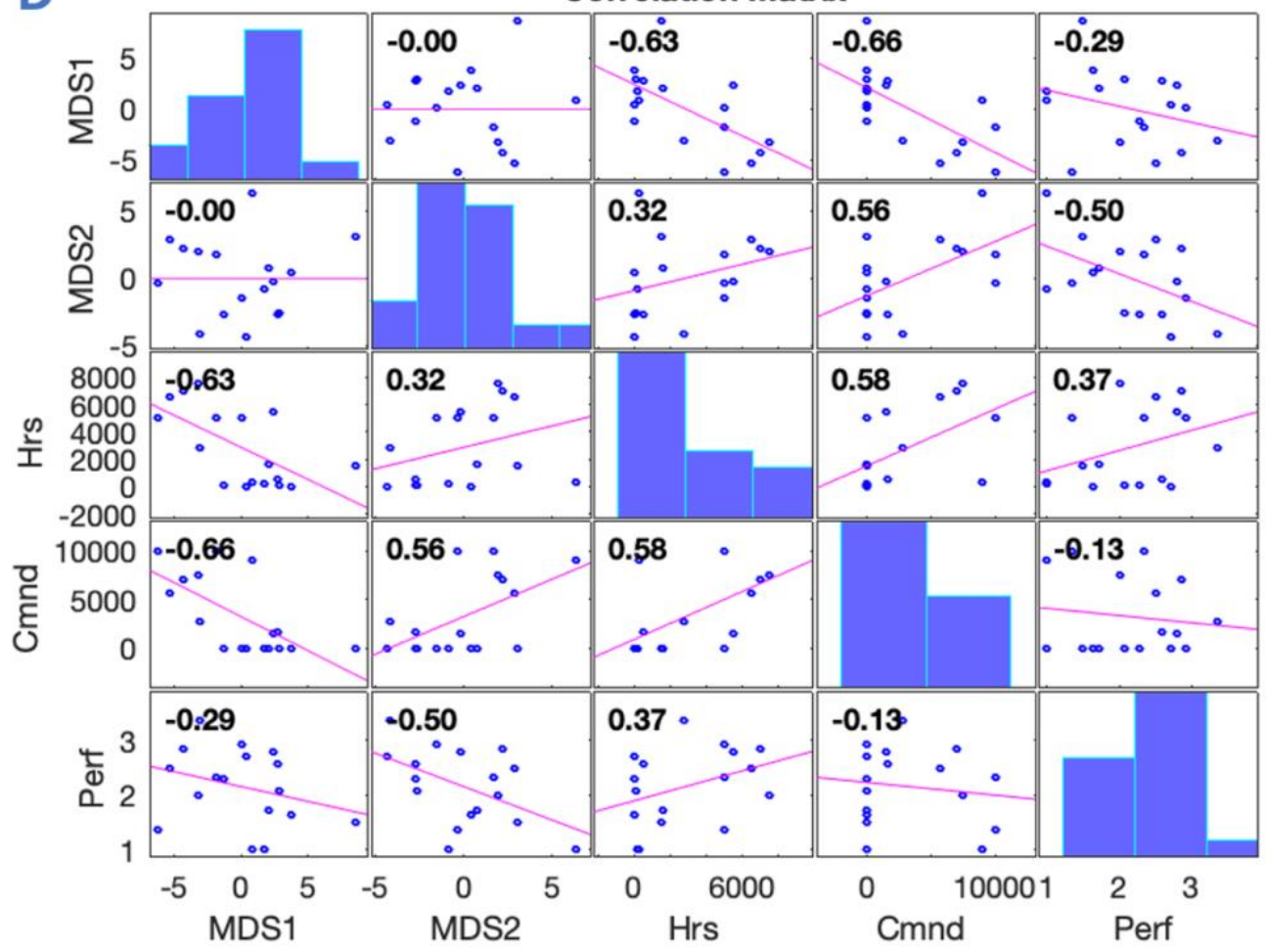

Figure 6 - Results of the Multidimensional Scaling. Panel C visualizes the first two MDS dimensions, where data points represent individual participants plotted in geometric space, so that dots closer to each other had more similar scanning strategies. Panel B shows the eigenvalues corresponding to the MDS dimensions, where the first two dimensions accounted for $86.67 \%$ of the variance. The correlation plot (Panel D) shows the relationship between the two principal MDS dimensions and our experience and performance metrics. 
In the present work we examined the fidelity and validity of an aircrew competency training simulation. VR offers many benefits for human factors training, including both pedagogical and practical advantages over physical training. However, it also has potential limitations in terms of realism and the likelihood of transfer of training. Consequently, VR training applications need to be developed and tested using evidence-based methods (Gray, 2019). We adopted a published framework for testing and evaluating simulated environments to explore whether the flight simulation met appropriate fidelity and validity criteria that would allow it to be an effective training tool (Harris, Bird, et al., 2020).

We firstly used self-report measures to assess the face validity of the simulation and whether users felt a sense of presence in the environment. Results (displayed in figure 2) indicated that users felt the simulation was realistic and could potentially be a useful training device. In addition, users reported feeling a sense of presence in the simulation, suggesting that it was of sufficient fidelity to create an immersive experience. Although these assessments certainly do not guarantee that the simulation will be effective for training, a failure to create a tool that has face validity would likely be a barrier to engagement from users. Nevertheless, expert assessments of fidelity and face validity are an important method for testing flight simulators (Perfect et al., 2014) and the data suggested that this was achieved.

Next, we aimed to test the construct validity of the simulation by 1) examining the relationship between eye movement behaviours and real-world expertise and 2) by examining the relationship between performance in the simulator tasks and real-world expertise. If the simulation is an accurate representation of the real task, then the differences between more and less skilled performers that are present in the real-world should also be present in the simulated environment. Previous research has shown that more experienced pilots show different visual search behaviours compared to their more novice counterparts (Haslbeck et al., 2012; Haslbeck \& Zhang, 2017; Yang et al., 2013; Ziv, 2016). Eye movement differences were also detected here, with the search behaviours of more experienced pilots typically characterised by a reduced search rate and a more predictable pattern of visual fixations, quantified by lower gaze transition 
experienced pilots used similar overall strategies, which, as the correlation analysis showed, was made up of a lower entropy scan path and fewer antipersistent saccades, plus fewer fixations and a reduced search rate. Crucially, the MDS dimensions were related to both experience and performance. These results suggests that more experienced pilots performed a more efficient search of the cockpit, driven by their greater domain-specific knowledge, and were able to use their gaze in a more strategic fashion to locate areas of interest more easily.

Our second method of assessing construct validity provided no additional evidence to support the validity of the environment, as prior flight experience was not correlated with trainer ratings of performance. However, this may reflect a lack of sensitivity in the manual scoring system, rather than a lack of validity of the overall environment. Given that the environment was sensitive to eye movement differences in expertise it seems likely that the scoring system was just not sensitive to these differences. Indeed, the accompanying lack of a relationship between the performance scores and the separate eye movement variables (Table 4) seems to indicate this. An additional limitation of this approach was the use of a single expert rater, so future work could use multiple raters to ensure consistency and triangulate scores. Consequently, it will be important to further develop this performance scoring system in future iterations of the simulation. The lack of real-world performance data in the study could be considered a limitation, and future work should look to also compare real-world performance assessments, not just measures of experience.

\section{Conclusions}

VR training is being rapidly adopted in many high performance environments

498 (Bird, 2019; Gray, 2019; Hagita et al., 2020; Lele, 2013; Mathew et al., 2021), but

499 methods of assessing and validating the effectiveness of these environments are

500 lagging behind technology uptake. By adopting and implementing the recommendations of a recent framework for simulation testing (Harris, Bird, et al., 2020) we aimed to 1) test an aircrew training simulation and 2) demonstrate some of the methods for conducting evidence-based testing of VR training. The results indicated that expert pilots generally thought the simulation was realistic and potentially useful for training. The construct validity and psychological fidelity of the simulation was also supported as differences in visual expertise were clearly detectable. Importantly, the performance assessment criteria were not sufficiently sensitive to real-world expertise, 

applications.

512 Adanov, L., Efthymiou, M., \& Macintyre, A. (2020). An Exploratory Study of Pilot Training and

513 Recruitment in Europe. International Journal of Aviation Science and Technology,

514 01(02), 44-51. https://doi.org/10.23890/IJAST.vm01is02.0201

515 Allsop, J., \& Gray, R. (2014). Flying under pressure: Effects of anxiety on attention and gaze

516 behavior in aviation. Journal of Applied Research in Memory and Cognition, 3(2), 63-71.

$517 \quad$ https://doi.org/10.1016/j.jarmac.2014.04.010

518 Amor, T. A., Reis, S. D. S., Campos, D., Herrmann, H. J., \& Andrade, J. S. (2016). Persistence

$519 \quad$ in eye movement during visual search. Scientific Reports, 6(1), 20815.

$520 \quad$ https://doi.org/10.1038/srep20815

521 Baños, R. m., Botella, C., Alcañiz, M., Liaño, V., Guerrero, B., \& Rey, B. (2004). Immersion and

522 Emotion: Their Impact on the Sense of Presence. CyberPsychology \& Behavior, 7(6),

523 734-741. https://doi.org/10.1089/cpb.2004.7.734

524 Barnett, S. M., \& Ceci, S. J. (2002). When and where do we apply what we learn?: A taxonomy

525 for far transfer. Psychological Bulletin, 128(4), 612-637. https://doi.org/10.1037/0033-

$526 \quad 2909.128 .4 .612$

527 Bird, J. M. (2019). The use of virtual reality head-mounted displays within applied sport

$528 \quad$ psychology. Journal of Sport Psychology in Action, 1-14.

$529 \quad$ https://doi.org/10.1080/21520704.2018.1563573

530 Borg, I., \& Groenen, P. J. F. (2005). Modern Multidimensional Scaling: Theory and Applications.

$531 \quad$ Springer Science \& Business Media.

532 Botella, C., García-Palacios, A., Villa, H., Baños, R. M., Quero, S., Alcañiz, M., \& Riva, G.

533 (2007). Virtual reality exposure in the treatment of panic disorder and agoraphobia: A

$534 \quad$ controlled study. Clinical Psychology \& Psychotherapy, 14(3), 164-175.

$535 \quad$ https://doi.org/10.1002/cpp.524

536 Brams, S., Ziv, G., Levin, O., Spitz, J., Wagemans, J., Williams, A. M., \& Helsen, W. F. (2019).

$537 \quad$ The relationship between gaze behavior, expertise, and performance: A systematic

538 review. Psychological Bulletin, 145(10), 980-1027. https://doi.org/10.1037/bul0000207

539 Bright, E., Vine, S., Wilson, M. R., Masters, R. S. W., \& McGrath, J. S. (2012). Face validity,

$540 \quad$ construct validity and training benefits of a virtual reality turp simulator. International

$541 \quad J o u r n a l$ of Surgery, 10(3), 163-166. https://doi.org/10.1016/j.ijsu.2012.02.012

542 Caro, P. W. (1973). Aircraft Simulators and Pilot Training. Human Factors, 15(6), 502-509.

$543 \quad$ https://doi.org/10.1177/001872087301500602

544 Causer, J., Holmes, P. S., \& Williams, A. M. (2011). Quiet Eye Training in a Visuomotor Control

$545 \quad$ Task. Medicine and Science in Sports and Exercise, 43(6), 1042-1049.

$546 \quad$ https://doi.org/10.1249/MSS.0b013e3182035de6

547 Dahlstrom, N., Dekker, S., Winsen, R., \& Nyce, J. (2009). Fidelity and validity of simulator

$548 \quad$ training. Theoretical Issues in Ergonomics Science, 10.

$549 \quad$ https://doi.org/10.1080/14639220802368864

550 Faul, F., Erdfelder, E., Lang, A.-G., \& Buchner, A. (2007). G*Power 3: A flexible statistical power

551 analysis program for the social, behavioral, and biomedical sciences. Behavior

552 Research Methods, 39(2), 175-191. https://doi.org/10.3758/BF03193146

553 Fooken, J., \& Spering, M. (2019). Decoding go/no-go decisions from eye movements. Journal of

$554 \quad$ Vision, 19(2), 5-5. https://doi.org/10.1167/19.2.5

555 Fooken, J., \& Spering, M. (2020). Eye movements as a readout of sensorimotor decision

556 processes. Journal of Neurophysiology, 123(4), 1439-1447.

$557 \quad$ https://doi.org/10.1152/jn.00622.2019

558 Freeman, S., Eddy, S. L., McDonough, M., Smith, M. K., Okoroafor, N., Jordt, H., \& Wenderoth,

559 M. P. (2014). Active learning increases student performance in science, engineering, 
560 and mathematics. Proceedings of the National Academy of Sciences, 111(23), 8410-

$561 \quad$ 8415. https://doi.org/10.1073/pnas.1319030111

562 Gegenfurtner, A., Lehtinen, E., \& Säljö, R. (2011). Expertise Differences in the Comprehension

563 of Visualizations: A Meta-Analysis of Eye-Tracking Research in Professional Domains.

564 Educational Psychology Review, 23(4), 523-552. https://doi.org/10.1007/s10648-011-

$565 \quad 9174-7$

566 Gray, R. (2019). Virtual environments and their role in developing perceptual-cognitive skills in

$567 \quad$ sports. In A.M. Williams \& R.C. Jackson (Eds.) Anticipation and Decision Making in

568 Sport. Taylor \& Francis, Routledge. https://doi.org/10.4324/9781315146270-19

569 Hagita, K., Kodama, Y., \& Takada, M. (2020). Simplified virtual reality training system for

$570 \quad$ radiation shielding and measurement in nuclear engineering. Progress in Nuclear

$571 \quad$ Energy, 118, 103127. https://doi.org/10.1016/j.pnucene.2019.103127

572 Harris, D. J., Bird, J. M., Smart, A. P., Wilson, M. R., \& Vine, S. J. (2020). A framework for the

573 testing and validation of simulated environments in experimentation and training.

$574 \quad$ Frontiers in Psychology, 11(605). https://doi.org/10.3389/fpsyg.2020.00605

575 Harris, D. J., Buckingham, G., Wilson, M. R., Brookes, J., Mushtaq, F., Mon-Williams, M., \&

576 Vine, S. J. (2021). Exploring sensorimotor performance and user experience within a

$577 \quad$ virtual reality golf putting simulator. Virtual Reality, 25(3), 647-654.

$578 \quad$ https://doi.org/10.1007/s10055-020-00480-4

579 Harris, D. J., Hardcastle, K. J., Wilson, M. R., \& Vine, S. J. (2021). Assessing the learning and

$580 \quad$ transfer of gaze behaviours in immersive virtual reality. Virtual Reality.

$581 \quad$ https://doi.org/10.1007/s10055-021-00501-w

582 Harris, D., Wilson, M., \& Vine, S. (2019). Development and validation of a simulation workload

583 measure: The simulation task load index (SIM-TLX). Virtual Reality, 24(4), 557-566.

$584 \quad$ https://doi.org/10.1007/s10055-019-00422-9

585 Hart, S. G., \& Staveland, L. E. (1988). Development of NASA-TLX (Task Load Index): Results

586 of empirical and theoretical research. In Advances in Psychology (Vol. 52, pp. 139-183).

$587 \quad$ Elsevier. https://doi.org/10.1016/S0166-4115(08)62386-9

588 Haslbeck, A., Schubert, E., Gontar, P., \& Bengler, K. (2012). The relationship between pilots'

589 manual flying skills and their visual behavior: A flight simulator study using eye tracking.

590 Haslbeck, A., \& Zhang, B. (2017). I spy with my little eye: Analysis of airline pilots' gaze patterns

591 in a manual instrument flight scenario. Applied Ergonomics, 63, 62-71.

$592 \quad$ https://doi.org/10.1016/j.apergo.2017.03.015

593 Janelle, C. M. (2002). Anxiety, arousal and visual attention: A mechanistic account of

594 performance variability. Journal of Sports Sciences, 20(3), 237-251.

$595 \quad$ https://doi.org/10.1080/026404102317284790

596 Janelle, C. M., \& Hatfield, B. D. (2008). Visual Attention and Brain Processes That Underlie

597 Expert Performance: Implications for Sport and Military Psychology. Military Psychology,

598 20(sup1), S39-S69. https://doi.org/10.1080/08995600701804798

$599 \quad$ JASP Team (2021). JASP (Version )[Computer software].

600 Krassanakis, V., Filippakopoulou, V., \& Nakos, B. (2014). EyeMMV toolbox: An eye movement

601 post-analysis tool based on a two-step spatial dispersion threshold for fixation

602 identification. Journal of Eye Movement Research, 7(1).

$603 \quad$ https://doi.org/10.16910/jemr.7.1.1

604 Landman, A., Groen, E. L., van Paassen, M. M. (René), Bronkhorst, A. W., \& Mulder, M. (2017).

605 Dealing With Unexpected Events on the Flight Deck: A Conceptual Model of Startle and

$606 \quad$ Surprise. Human Factors, 59(8), 1161-1172.

$607 \quad$ https://doi.org/10.1177/0018720817723428

608 Le Noury, P., Buszard, T., Reid, M., \& Farrow, D. (2020). Examining the representativeness of a

609 virtual reality environment for simulation of tennis performance. Journal of Sports

$610 \quad$ Sciences, 1-9. https://doi.org/10.1080/02640414.2020.1823618

611 Lele, A. (2013). Virtual reality and its military utility. Journal of Ambient Intelligence and

612 Humanized Computing, 4(1), 17-26. https://doi.org/10.1007/s12652-011-0052-4 
613 Lounis, C., Peysakhovich, V., \& Causse, M. (2021). Visual scanning strategies in the cockpit are 614 modulated by pilots' expertise: A flight simulator study. PLOS ONE, 16(2), e0247061.

$615 \quad$ https://doi.org/10.1371/journal.pone.0247061

616 Mann, D. L., Nakamoto, H., Logt, N., Sikkink, L., \& Brenner, E. (2019). Predictive eye

617 movements when hitting a bouncing ball. Journal of Vision, 19(14), 28-28.

$618 \quad$ https://doi.org/10.1167/19.14.28

619 Mann, Williams, A. M., Ward, P., \& Janelle, C. M. (2007). Perceptual-Cognitive Expertise in

620 Sport: A Meta-Analysis. Journal of Sport and Exercise Psychology, 29(4), 457-478.

$621 \quad$ https://doi.org/10.1123/jsep.29.4.457

622 Mathew, R. K., Collaboration, T. I. H., \& Mushtaq, F. (2021). Three principles for the progress of

623 immersive technologies in healthcare training and education. BMJ Simulation and

624 Technology Enhanced Learning, 7(5). https://doi.org/10.1136/bmjstel-2021-000881

625 Perfect, P., Timson, E., White, M. D., Padfield, G. D., Erdos, R., \& Gubbels, A. W. (2014). A

626 rating scale for the subjective assessment of simulation fidelity. The Aeronautical

627 Journal, 118(1206), 953-974. https://doi.org/10.1017/S0001924000009635

628 Prince, M. (2004). Does Active Learning Work? A Review of the Research. Journal of

629 Engineering Education, 93(3), 223-231. https://doi.org/10.1002/j.2168-

$630 \quad 9830.2004 . t b 00809 . x$

631 Salvucci, D. D., \& Goldberg, J. H. (2000). Identifying fixations and saccades in eye-tracking

632 protocols. Proceedings of the Symposium on Eye Tracking Research \& Applications -

633 ETRA '00, 71-78. https://doi.org/10.1145/355017.355028

634 Sankaranarayanan, G., Li, B., Manser, K., Jones, S. B., Jones, D. B., Schwaitzberg, S., Cao, C.

635 G. L., \& De, S. (2016). Face and construct validation of a next generation virtual reality

636 (Gen2-VRC) surgical simulator. Surgical Endoscopy, 30(3), 979-985.

$637 \quad$ https://doi.org/10.1007/s00464-015-4278-7

638 Shannon, C. E. (1948). A Mathematical Theory of Communication. Bell System Technical

639 Journal, 27(3), 379-423. https://doi.org/10.1002/j.1538-7305.1948.tb01338.x

640 Shannon, C. E., \& Weaver, W. (1949). The Mathematical Theory of Communication. Uol Press.

641 Slater, M. (2009). Place illusion and plausibility can lead to realistic behaviour in immersive

642 virtual environments. Philosophical Transactions of the Royal Society B: Biological

643 Sciences, 364(1535), 3549-3557. https://doi.org/10.1098/rstb.2009.0138

644 Slater, M., \& Sanchez-Vives, M. V. (2016). Enhancing Our Lives with Immersive Virtual Reality.

$645 \quad$ Frontiers in Robotics and Al, 3. https://doi.org/10.3389/frobt.2016.00074

646 Slater, M., Usoh, M., \& Steed, A. (1995). Taking steps: The influence of a walking technique on

647 presence in virtual reality. ACM Transactions on Computer-Human Interaction, 2(3),

648 201-219. https://doi.org/10.1145/210079.210084

649 Słowiński, P., Baldemir, H., Wood, G., Alizadehkhaiyat, O., Coyles, G., Vine, S., Williams, G.,

650 Tsaneva-Atanasova, K., \& Wilson, M. (2019). Gaze training supports self-organization of

651 movement coordination in children with developmental coordination disorder. Scientific

652 Reports, 9(1), 1-11. https://doi.org/10.1038/s41598-018-38204-z

653 Słowiński, P., Zhai, C., Alderisio, F., Salesse, R., Gueugnon, M., Marin, L., Bardy, B. G., di

654 Bernardo, M., \& Tsaneva-Atanasova, K. (2016). Dynamic similarity promotes

655 interpersonal coordination in joint action. Journal of The Royal Society Interface,

656 13(116), 20151093. https://doi.org/10.1098/rsif.2015.1093

657 Sudiarno, A., \& Wahyuni, A. D. (2020). Analysis of Human Factors and Workloads in

$658 \quad$ Earthquake Disaster Evacuation Simulations Using Virtual Reality Technology. IOP

$659 \quad$ Conference Series: Materials Science and Engineering, 1003, 012082.

$660 \quad$ https://doi.org/10.1088/1757-899X/1003/1/012082

661 Sweller, J. (1988). Cognitive load during problem solving: Effects on learning. Cognitive

662 Science, 12(2), 257-285. https://doi.org/10.1016/0364-0213(88)90023-7

663 Tabachnick, B. G., \& Fidell, L. S. (1996). Using multivariate statistics. Northridge. Cal.: Harper

664 Collins.

665 Usoh, M., Catena, E., Arman, S., \& Slater, M. (2000). Using presence questionnaires in reality.

666 Presence: Teleoperators and Virtual Environments, 9(5), 497-503.

$667 \quad$ https://doi.org/10.1162/105474600566989 
668 Valenta, V. (2018). Effects of Airline Industry Growth on Pilot Training. MAD - Magazine of $669 \quad$ Aviation Development, 6(4), 52-56. https://doi.org/10.14311/MAD.2018.04.06

670 van Doorn, J., van den Bergh, D., Bohm, U., Dablander, F., Derks, K., Draws, T., Evans, N. J., 671 Gronau, Q. F., Hinne, M., Kucharský, Š., Ly, A., Marsman, M., Matzke, D., Raj, A., 672 Sarafoglou, A., Stefan, A., Voelkel, J. G., \& Wagenmakers, E.-J. (2019). The JASP 673 Guidelines for Conducting and Reporting a Bayesian Analysis [Preprint]. PsyArXiv. $674 \quad$ https://doi.org/10.31234/osf.io/yqxfr

675 Vine, S. J., Uiga, L., Lavric, A., Moore, L. J., Tsaneva-Atanasova, K., \& Wilson, M. R. (2015).

676 Individual reactions to stress predict performance during a critical aviation incident.

$677 \quad$ Anxiety, Stress, \& Coping, 28(4), 467-477.

$678 \quad$ https://doi.org/10.1080/10615806.2014.986722

679 Vine, S. J., \& Wilson, M. R. (2011). The influence of quiet eye training and pressure on attention 680 and visuo-motor control. Acta Psychologica, 136(3), 340-346.

$681 \quad$ https://doi.org/10.1016/j.actpsy.2010.12.008

682 Williams, A. M., Davids, K., Burwitz, L., \& Williams, J. G. (1994). Visual Search Strategies in 683 Experienced and Inexperienced Soccer Players. Research Quarterly for Exercise and $684 \quad$ Sport, 65(2), 127-135. https://doi.org/10.1080/02701367.1994.10607607

685 Wilson, M. R., Causer, J., \& Vickers, J. N. (2015). The quiet eye as a characteristic of expertise. 686 In Routledge Handbook of Sport Expertise (pp. 22-37).

687 Wood, G., Wright, D. J., Harris, D., Pal, A., Franklin, Z. C., \& Vine, S. J. (2020). Testing the

688 construct validity of a soccer-specific virtual reality simulator using novice, academy, and 689 professional soccer players. Virtual Reality. https://doi.org/10.1007/s10055-020-00441-x 690 Yang, J. H., Kennedy, Q., Sullivan, J., \& Fricker, R. D. (2013). Pilot Performance: Assessing 691 How Scan Patterns \& Navigational Assessments Vary by Flight Expertise. Aviation, 692 Space, and Environmental Medicine, 84(2), 116-124.

$693 \quad$ https://doi.org/10.3357/ASEM.3372.2013

694 Ziv, G. (2016). Gaze Behavior and Visual Attention: A Review of Eye Tracking Studies in 695 Aviation. The International Journal of Aviation Psychology, 26(3-4), 75-104.

696 https://doi.org/10.1080/10508414.2017.1313096

697 